\title{
WILL BEQUESTS ATTENUATE THE PREDICTED MELTDOWN IN STOCK PRICES WHEN BABY BOOMERS RETIRE?
}

\author{
Andrew B. Abel \\ Working Paper 8131 \\ http://www.nber.org/papers/w8131 \\ NATIONAL BUREAU OF ECONOMIC RESEARCH \\ 1050 Massachusetts Avenue \\ Cambridge, MA 02138 \\ February 2001
}

This paper was prepared as a discussion of "Demographic Structure and Asset Returns," presented by James Poterba at the Review of Economics and Statistics Lecture, Cambridge, Massachusetts, March 20, 2000. I thank Bill Dupor, Yoel Lax, Nick Souleles, and Amir Yaron for helpful discussion. The views expressed herein are those of the author and not necessarily those of the National Bureau of Economic Research.

(C) 2001 by Andrew B. Abel. All rights reserved. Short sections of text, not to exceed two paragraphs, may be quoted without explicit permission provided that full credit, including $\odot$ notice, is given to the source. 
Will Bequests Attenuate the Predicted Meltdown in Stock Prices When Baby Boomers Retire? Andrew B. Abel

NBER Working Paper No. 8131

February 2001

JEL No. G12

\begin{abstract}
Jim Poterba finds that consumers do not spend all of their assets during retirement, and he projects that the demand for assets will remain high when the baby boomers retire. Based on his forecast of continued high demand for capital, Poterba rejects the asset market meltdown hypothesis, which predicts a fall in stock prices when the baby boomers retire. I develop a rational expectations general equilibrium model with a bequest motive and an aggegate supply curve for capital. In this model, a baby boom generates an increase in stock prices, and stock prices are rationally anticipated to fall when the baby boomers retire, even though, as emphasized by Poterba, consumers do not spend all of their assets during retirement. This finding contradicts Poterba's conclusion that continued high demand for assets by retired baby boomers will prevent a fall in the price of capital.
\end{abstract}

Andrew B. Abel

The Wharton School

University of Pennsylvania

2315 Steinberg-Dietrich Hall

Philadelphia, PA 19104

and NBER

abel@wharton.upenn.edu 
There are many potential explanations of the phenomenal increase in stock prices in the United States during the past several years. One popular explanation is that as baby boomers save for retirement, their aggregate demand for capital is very large, which drives up the price of capital. This explanation then goes on to predict that when the baby boomers retire, they will sell large amounts of capital and drive down its price. Jim Poterba uses the term "asset market meltdown hypothesis" to refer to this predicted decline in stock prices.

Poterba examines data on asset holdings in several cross sections of the Survey of Consumer Finances (SCF) and raises an important challenge to the asset market meltdown hypothesis. He points out that recent theoretical models of a market meltdown assume that baby boomers will sell all of their assets during their retirement years, ${ }^{1}$ and he argues that this assumption is inconsistent with the data on asset holdings in the SCF. Subject to the difficulty of disentangling time effects, cohort effects, and age effects, Poterba concludes from his Tables 1 and 2 that although consumers rapidly accumulate assets while they are of working age, they decumulate assets during retirement much less rapidly than would be predicted by a simple life-cycle model with no bequest motive and no lifetime uncertainty. He extrapolates from these results to conclude that the baby boomers will not sell all of their assets during retirement, and he further concludes that the asset market meltdown hypothesis is incorrect in its prediction that the price of capital will fall.

Poterba also looks for empirical evidence of an effect of demographic variables on asset prices and returns. He finds a very weak effect of demographic variables on asset returns, but he finds a more substantial effect of demographic variables on stock prices using data he generates on "projected asset demands." Poterba calculates projected asset demands by combining agespecific asset holdings from his Table 2 with actual and projected age-specific populations in each year. He finds (Table 13) some evidence of a positive relationship between projected asset demands and the price-dividend ratio over various historical sample periods dating back to 1926. Looking forward, the projected asset demands reported in his Table 5 increase over the next two decades and then remain fairly constant for the succeeding three decades.

\footnotetext{
${ }^{1}$ Abel (2000) and Brooks (1999) both assume that consumers know precisely when they will die and do not have bequest motives so that they optimally choose to have zero wealth at the time of death.
} 
Because projected asset demands do not fall when the baby boomers retire, Poterba rejects the asset market meltdown hypothesis while maintaining the notion that the baby boom contributed to the increase in stock prices.

Poterba has demonstrated that, in contrast to the predictions of a lifecycle model with no bequest motive and no lifetime uncertainty, the projected demand for assets will not decline sharply when the baby boomers are retired. I will accept this conclusion, but I will argue here that the failure of the demand for capital to fall in the future does not imply that the price of capital will not fall. Specifically, taking account of the supply of capital, as well as its demand, the equilibrium price of capital may fall when baby boomers retire, even if the the demand for capital by retired baby boomers remains high.

In this paper, I present a general equilibrium overlapping generations model with convex adjustment costs, which generate an endogenous price of capital as in Abel (2000). I include a bequest motive so that consumers will choose not to consume all of their wealth during retirement. The inclusion of a bequest motive provides a framework for addressing the extent to which the predicted meltdown in asset prices is attenuated by taking account of the fact that consumers do not consume all of their wealth during retirement. The equilibrium of the model has the following properties: (1) the price of capital rises when a large cohort of consumers-baby boomers-is young and working, which is consistent with Poterba's Tables 5 and 13; (2) the price of capital is anticipated to fall when baby boomers retire; (3) young baby boomers optimally choose to hold capital even with the anticipation that its price will fall; (4) consumers do not completely decumulate their assets during retirement, consistent with Poterba's Tables 1 and 2; and yet (5) the dynamic behavior of the equilibrium price of capital is unaffected by the strength of the bequest motive, so that assets held by old consumers for the purpose of making bequests do not attenuate the predicted drop in the price of capital when baby boomers retire.

I develop and analyze the formal overlapping generations model in Section 2. Before presenting this formal model, in Section 1 I present Poterba's heuristic model and augment it to include the supply of capital as well as the demand for capital. The discussion in Section 1 provides an intuitive preview of the formal results in Section 2. 


\section{A Heuristic Model}

Poterba presents a simple stylized, or heuristic, model to illustrate the effects of demographic variables on the price of capital. I will begin by presenting this model, with slightly modified notation.

Consider a closed economy with overlapping generations of consumers who live for two periods. All consumers who are born in the same period are identical. Let $N_{t}$ be the number of consumers born at the beginning of period $t$. They inelastically supply one unit of labor when they are young, and they do not work when they are old, so the amount of labor employed in period $t$ is $N_{t}$. Let

$$
\eta_{t+1} \equiv \frac{N_{t+1}}{N_{t}}
$$

be the birth rate in period $t+1$, and assume that the birth rate is a serially uncorrelated random variable.

To make the analysis transparent, Poterba makes additional simplifying assumptions. He assumes that the capital stock cannot be augmented by investment and does not depreciate. Therefore, $K_{t}$, the aggregate capital stock held at the beginning of period $t$, remains constant over time. He also assumes that in each period, the wage income of each young consumer equals one unit of output ${ }^{2}$ and that young consumers save a constant fraction $s$ of their wage income. Therefore, the aggregate saving of the cohort of young consumers born at the beginning of period $t$ is $N_{t} s$. All of this saving is used to purchase $K_{t+1}$, the aggregate capital stock to be carried into period $t+1$, at a price of $q_{t}$ per unit of capital in period $t$. Therefore,

$$
q_{t} K_{t+1}=N_{t} s
$$

which is equivalent to Poterba's equation (1).

Equation (2) can be interpreted as the demand for capital, $K_{t+1}$, at the end of period $t$ as a function of the price of capital, $q_{t}$, given $N_{t}$ and $s$. If the capital stock remains constant, as in Poterba's stylized model, then the price of capital can be determined directly from this demand curve. In particular, the price of capital, $q_{t}$, is proportional to $N_{t}$, the number of workers in the

\footnotetext{
${ }^{2}$ The aggregate production function implicitly underlying this model is $Y_{t}=N_{t}+f\left(K_{t}\right)$, where $Y_{t}$ is aggregate output. With this specification of the production function, the marginal product of labor always equals one, regardless of the level of the capital stock.
} 
economy. Thus, an increase in $N_{t}$ will increase the price of capital, $q_{t}$, as the large cohort of workers bids up the price of the fixed capital stock. Poterba goes on to claim that when the large cohort of workers retires and sells its capital, it will drive down the price of capital. This claim is based on the implicit assumption that a baby boom in period $t$, which generates a large cohort of workers, $N_{t}$, will be followed by a decrease in the size of the working population in the following generation. That is, Poterba assumes that $N_{t+1}$ is smaller than $N_{t}$. Equivalently, he assumes that if the birth rate in period $t, \eta_{t}$, is large, then the birth rate in the following period, $\eta_{t+1}$, must not only be small, it must be less than one. ${ }^{3}$ This assumption requires strong negative serial correlation in the birth rate across successive generations. ${ }^{4}$ However, if the economy has a fluctuating birth rate that always exceeds one, so that the population of workers always grows over time, then in the stylized model introduced by Poterba, and represented by equation (2), the price of capital increases in every period.

In the presence of a growing population, the price of capital in equation (2) can be prevented from growing in every period by allowing the capital stock to grow over time. To preview the rational expectations general equilibrium model that I present in Section 2, suppose the aggregate supply curve of capital slopes upward so that the (gross) growth rate of the capital stock, $\frac{K_{t+1}}{K_{t}}$, is an increasing function of the price of capital. In particular, suppose that

$$
K_{t+1}=\kappa K_{t} q_{t}^{\lambda}
$$

where $\kappa>0$ and $\lambda>0 .{ }^{5}$ Equation (3) represents the supply of capital, $K_{t+1}$, at the end of period $t$ as a function of the price of capital, $q_{t}$, for a given value of $K_{t}$.

To determine the equilibrium price of capital, I will solve the demand and supply curves in equations (2) and (3) simultaneously. First divide both sides of equation (3) by $N_{t+1}$, and use the definition of the birth rate,

\footnotetext{
${ }^{3} \mathrm{~A}$ birth rate equal to one in the model corresponds to one child per person, which is equivalent to two children per woman.

${ }^{4}$ In contrast, if the birth rate is i.i.d. across successive generations, an increase in $N_{t}$, which increases $q_{t}$, is no more likely to be followed by a decrease in the number of workers or in the price of capital in the following period than at any other time.

${ }^{5}$ If $\lambda$ were equal to zero, and if $\kappa$ were equal to one, the capital stock would be constant over time, as in Poterba's model.
} 
$\eta_{t+1}$, in equation (1) to obtain

$$
k_{t+1}=\kappa k_{t} \frac{1}{\eta_{t+1}} q_{t}^{\lambda}
$$

where $k_{t+1} \equiv K_{t} / N_{t}$ is the capital-labor ratio in period $t$. To express the capital-labor ratio $k_{t}$ as a function of $q_{t}$, use equation (3) to substitute for $K_{t+1}$ in equation (2), and use the definition of $k_{t}$ to obtain

$$
k_{t}=\frac{1}{\kappa} s q_{t}^{-(1+\lambda)}
$$

To obtain an expression for the dynamic behavior of the price of capital, $q_{t}$, substitute equation (5) into equation (4) to obtain

$$
\ln q_{t}=\frac{1}{1+\lambda} \ln q_{t-1}-\frac{1}{1+\lambda} \ln \kappa+\frac{1}{1+\lambda} \ln \eta_{t} .
$$

Since $\lambda>0$, if the birth rate, $\ln \eta_{t}$, is serially uncorrelated with unconditional mean $E(\ln \eta)$, then $\ln q_{t}$ follows a stationary $\operatorname{AR}(1)$ process with unconditional mean $\frac{1}{\lambda}(E\{\ln \eta\}-\ln \kappa)$. Thus, starting from the unconditional mean price of capital, an increase in the birth rate $\eta_{t}$ causes an increase in the price of capital $q_{t}$. Consistent with the asset market meltdown hypothesis, the price of capital, $\ln q_{t+1}$, is anticipated to fall toward its unconditional mean in the following period.

In the heuristic model presented here, as well as in the general equilibrium models in Abel (2000) and Brooks (1999), consumers spend all of their resources in the final period of life, contrary to the empirical findings reported by Poterba in his Tables 1 and 2. Poterba argues that since consumers continue to hold assets throughout old age, the aggregate demand for capital does not fall when the baby boomers age, and hence, contrary to the asset market meltdown hypothesis, the price of capital will not plunge when the baby boomers are retired. I was intrigued by Poterba's argument that the meltdown would be attenuated by the fact that people hold substantial assets until death, and I set out to examine the extent of this attenuation in the context of a rational expectations general equilibrium model that I present in Section 2. To address this issue, I assume that consumers have bequest motives, and thus hold assets at the time of death. In the specification I use in Section 2, the equilibrium dynamics of the price of capital are completely unaffected by the presence of a bequest motive and the consequent holding of 


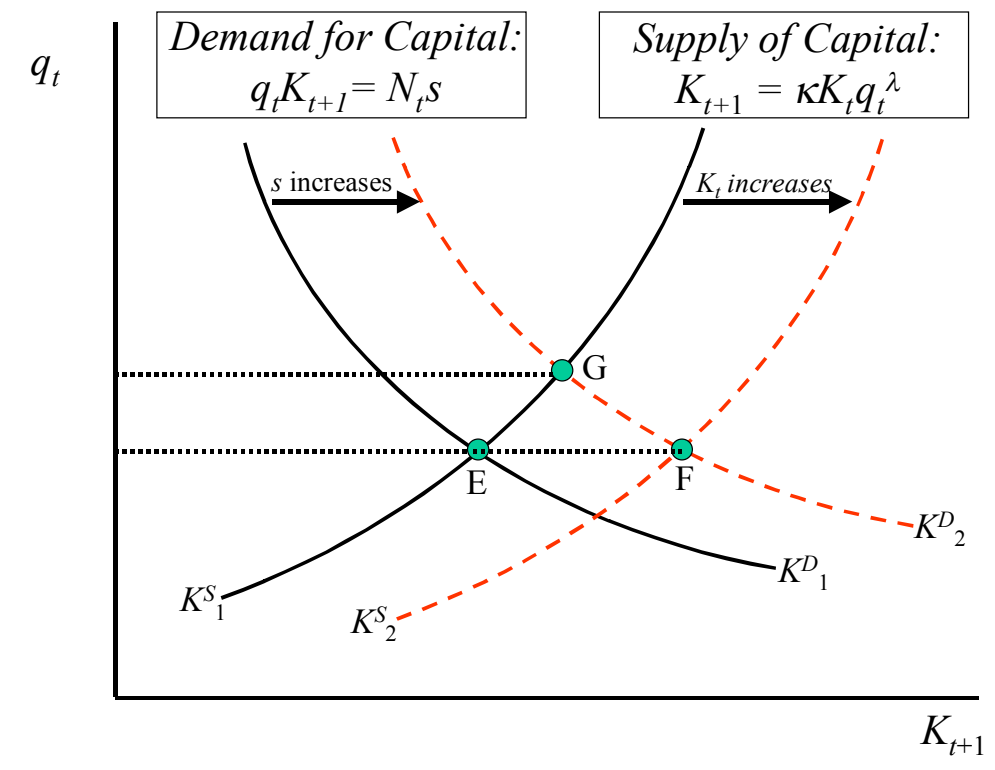

Figure 1: Supply and Demand for Capital

assets at the time of death. Therefore, a bequest motive does not attenuate the predicted decline in stock prices when the baby boom retires.

Before proceeding to the general equilibrium model, I will use the analysis in the current section to illustrate the invariance of the price of capital to the strength of the bequest motive. Figure 1 illustrates the demand and supply curves for capital, $K_{t+1}$, in period $t$ as a function of the price of capital, $q_{t}$. The solid downward-sloping curve, $K_{1}^{D}$, is the demand for capital in equation (2) in the absence of a bequest motive. The solid upward-sloping curve, $K_{1}^{S}$, is the supply of capital in equation (3) in the absence of a bequest motive. Thus, in the absence of a bequest motive, equilibrium in the market for capital in period $t$ is represented by point $E$.

Now consider an otherwise-identical economy with a bequest motive. The amount of saving, and hence the demand for capital, in period $t$ will be higher in the economy with a bequest motive than in the economy without a 
bequest motive. Thus, the demand for capital in an economy with a bequest motive is represented by $K_{2}^{D}$, which is to the right of $K_{1}^{D}{ }^{6}$ If the supply curve of capital were invariant to the strength of the bequest motive (which is implicitly assumed by Poterba), the equilibrium in the economy with a bequest motive would be represented by point $G$, where the price of capital is higher than in the absence of a bequest motive. However, an economy with a bequest motive will have a higher capital stock in each period than an otherwise-identical economy without a bequest motive. Therefore, in period $t$, the capital stock, $K_{t}$, is higher in the presence of a bequest motive than in its absence, and hence the supply curve of capital in the economy with a bequest motive, $K_{2}^{S}$, is to the right of the supply curve in the absence of a bequest motive, $K_{1}^{S}$. The equilibrium in the economy with a bequest motive is represented by point $F$, where $K_{2}^{D}$ and $K_{2}^{S}$ intersect, with a higher capital stock, but the same price of capital, as at point $E$. In the parametric rational expectations general equilibrium model in Section 2, I show that the equilibrium price of capital, $q_{t}$, is invariant to the strength of the bequest motive, which means that rightward shifts of the supply and demand curves in Figure 1 are of the same size. Since the equilibrium price of capital is not affected by strength of the bequest motive, the asset market meltdown is not attenuated by the introduction of a bequest motive.

\section{A General Equilibrium Model with a Baby Boom and an Endogenous Price of Capital}

In this section, I present a rational expectations general equilibrium model in which the wage income of workers is determined endogenously, and the asset demands of young and old consumers maximize expected lifetime utility. This model is a simplified version of the model in Abel (2000), except that it includes a bequest motive so that consumers will not completely decumulate their assets in old age.

As in Section 1, consider a closed economy with overlapping generations of consumers who live for two periods. At the beginning of period $t, N_{t}$ identical consumers are born, and they each inelastically supply one unit of labor in period $t$ and earn wage income $w_{t}$, which I will derive after introducing the

\footnotetext{
${ }^{6}$ The economy with a bequest motive can be viewed as having a higher value of saving per worker, $s$, than does the economy without a bequest motive.
} 
production technologies below. These consumers do not work in period $t+1$ when they are old.

\subsection{Production Technologies}

There are two production technologies. One technology, which I will call the consumption goods technology, produces output that can be either consumed or used as an input to the other technology, which is the capital adjustment technology.

The consumption goods technology uses capital and labor to produce output. Let $K_{t}$ be the aggregate capital stock at the beginning of period $t$, let $Y_{t}$ be the aggregate output of the consumption goods technology in period $t$, and assume that

$$
Y_{t}=A K_{t}^{\alpha} N_{t}^{1-\alpha}, \quad \text { where } 0<\alpha<1 \text { and } A>0 .
$$

The capital adjustment technology uses output from the consumption goods technology together with capital to produce capital for use in the following period. Suppose that the capital adjustment technology is

$$
K_{t+1}=a I_{t}^{\phi} K_{t}^{1-\phi},
$$

where $a>0,0<\phi<1$, and investment, $I_{t}$, is the aggregate quantity of output from the consumption goods technology used in the capital adjustment technology. Because the curvature parameter $\phi$ is strictly between zero and one, the capital stock in period $t+1$ is an increasing and concave function of investment, $I_{t}$. The concavity of this function captures convex costs of adjustment.

The price of capital at the end of period $t, q_{t}$, is the amount of consumption goods in period $t$ that must be used to produce an additional unit of capital for use in period $t+1$. Thus, $q_{t}=\left(\frac{\partial K_{t+1}}{\partial I_{t}}\right)^{-1}$, which can be calculated using equation (8) to obtain 7

$$
q_{t}=\frac{1}{a \phi}\left(\frac{I_{t}}{K_{t}}\right)^{1-\phi}
$$

\footnotetext{
${ }^{7}$ Equations (8) and (9) imply that $\frac{K_{t+1}}{K_{t}}=a^{\frac{1}{1-\phi}}\left(\phi q_{t}\right)^{\frac{\phi}{1-\phi}}$, which implies that in equation (3) $\lambda=\frac{\phi}{1-\phi}$ and $\kappa=a^{\frac{1}{1-\phi}} \phi^{\frac{\phi}{1-\phi}}$.
} 
The value, in terms of consumption goods in period $t$, of the capital stock carried into period $t+1$ equals the product of $q_{t}$ from equation (9) and $K_{t+1}$ from equation (8), which is

$$
q_{t} K_{t+1}=\frac{1}{\phi} I_{t}
$$

Factor markets are perfectly competitive so that each factor of production earns its marginal product. Thus, using equation (7) the wage rate in period $t, w_{t}$, is

$$
w_{t}=(1-\alpha) \frac{Y_{t}}{N_{t}}
$$

Because capital is used in both the consumption goods technology and the capital adjustment technology, capital earns rentals in both technologies. The rental earned by a unit of capital in the consumption goods technology in period $t$ is $\alpha \frac{Y_{t}}{K_{t}}$. The rental earned by a unit of capital in the capital adjustment technology in period $t$ is the marginal product of capital in that technology, $\frac{\partial K_{t+1}}{\partial K_{t}}$, multiplied by the current price of next period's capital, $q_{t}$. This rental can be calculated using equations (8) and (9) to obtain $\frac{1-\phi}{\phi} \frac{I_{t}}{K_{t}}$. Therefore, the total rental to capital is

$$
\nu_{t}=\alpha \frac{Y_{t}}{K_{t}}+\frac{1-\phi}{\phi} \frac{I_{t}}{K_{t}} .
$$

The (gross) rate of return on capital held from period $t-1$ to period $t, R_{t}$, equals the rental on capital, $\nu_{t}$, divided by the price paid for the capital in period $t-1, q_{t-1}$. Therefore,

$$
R_{t}=\frac{\alpha Y_{t}+\frac{1-\phi}{\phi} I_{t}}{q_{t-1} K_{t}} .
$$

\subsection{Consumer Behavior}

A consumer born at the beginning of period $t$ chooses consumption when young, $c_{t}$, consumption when old, $x_{t+1}$, and a bequest, $b_{t+2}$, to be divided equally among the consumer's $\eta_{t+1}$ children at the beginning of period $t+2$ when the consumer's children are beginning the second period of life. Each

consumer born at the beginning of period $t$ receives a bequest $\frac{b_{t+1}}{\eta_{t}}$ at the 
beginning of period $t+1$. Thus, the present value of the lifetime resources of a consumer born at the beginning of period $t$ is

$$
\theta_{t} \equiv w_{t}+\frac{1}{R_{t+1}} \frac{b_{t+1}}{\eta_{t}}
$$

The lifetime budget constraint of a consumer born at the beginning of period $t$ is

$$
c_{t}+\frac{1}{R_{t+1}} x_{t+1}+\frac{1}{R_{t+1}} \frac{1}{R_{t+2}} b_{t+2}=\theta_{t} .
$$

A consumer born at the beginning of period $t$ has the utility function

$$
U_{t}=\ln c_{t}+\beta E_{t}\left\{\ln x_{t+1}\right\}+\gamma E_{t}\left\{\ln b_{t+2}\right\},
$$

where $0<\beta \leq 1, \gamma \geq 0$, and $E_{t}\{\}$ denotes the expectation conditional on information available in period $t$. The consumer chooses $c_{t}, x_{t+1}$, and $b_{t+2}$ to maximize the utility function in equation (16) subject to the budget constraint in equation (15). It can be shown that the optimal value of consumption when young is ${ }^{8}$

$$
c_{t}=\frac{1}{1+\beta+\gamma} \theta_{t}
$$

At the beginning of period $t+1$, all of the capital in the economy, $K_{t+1}$, is held by the $N_{t}$ consumers who were born at the beginning of period $t$. They acquired some of this capital by saving when they were young, and they inherited the remaining portion of their capital. The rental accruing to the aggregate capital held by these consumers is $\nu_{t+1} K_{t+1}$, where $\nu_{t+1}$ is the rental to capital in equation (12). Therefore, each owner of capital has resources equal to

$$
\nu_{t+1} \frac{K_{t+1}}{N_{t}}=\frac{1}{N_{t}}\left(\alpha Y_{t+1}+\frac{1-\phi}{\phi} I_{t+1}\right) .
$$

\footnotetext{
${ }^{8}$ Define $\varphi_{t+1} \equiv\left(\theta_{t}-c_{t}\right) R_{t+1}$ and $V_{t+1}\left(\varphi_{t+1}\right) \equiv \max _{x_{t+1}, b_{t+2}} \beta \ln x_{t+1}+$ $\gamma E_{t+1}\left\{\ln b_{t+2}\right\}$ subject to $x_{t+1}+\frac{b_{t+2}}{R_{t+2}}=\varphi_{t+1}$. The optimal values of $x_{t+1}$ and $b_{t+2}$ are $x_{t+1}=\frac{\beta}{\beta+\gamma} \varphi_{t+1}$ and $b_{t+2}=\frac{\gamma}{\beta+\gamma} \varphi_{t+1} R_{t+2}$. Therefore, $V_{t+1}\left(\varphi_{t+1}\right)=$ $(\beta+\gamma) \ln \varphi_{t+1}+\beta \ln \frac{\beta}{\beta+\gamma}+\gamma \ln \frac{\gamma}{\beta+\gamma}+\gamma E_{t+1}\left\{\ln R_{t+2}\right\}$. The optimal value of $c_{t}$ maximizes $\ln c_{t}+E_{t}\left\{V_{t+1}\left(\varphi_{t+1}\right)\right\}$ which is the value of $c_{t}$ that maximizes $\ln c_{t}+(\beta+\gamma) E_{t}\left\{\ln \varphi_{t+1}\right\}$, or equivalently, the value of $c_{t}$ that maximizes $\ln c_{t}+(\beta+\gamma) \ln \left(\theta_{t}-c_{t}\right)$. The first-order condition for this maximization is $\frac{1}{c_{t}}=\frac{\beta+\gamma}{\theta_{t}-c_{t}}$, which implies $(1+\beta+\gamma) c_{t}=\theta_{t}$.
} 
The owners of this capital (who were born at the beginning of period $t$ ) are in final period of their lives in period $t+1$, and they choose consumption, $x_{t+1}$, and a bequest, $b_{t+2}$, to maximize $\beta \ln x_{t+1}+\gamma E_{t+1}\left\{\ln b_{t+2}\right\}$ subject to $x_{t+1}+\frac{1}{R_{t+2}} b_{t+2}=\frac{\alpha Y_{t+1}+\frac{1-\phi}{\phi} I_{t+1}}{N_{t}}$. The optimal values of $x_{t+1}$ and $b_{t+2}$ are

$$
x_{t+1}=\frac{\beta}{\beta+\gamma} \frac{1}{N_{t}}\left(\alpha Y_{t+1}+\frac{1-\phi}{\phi} I_{t+1}\right)
$$

and

$$
\frac{b_{t+2}}{R_{t+2}}=\frac{\gamma}{\beta+\gamma} \frac{1}{N_{t}}\left(\alpha Y_{t+1}+\frac{1-\phi}{\phi} I_{t+1}\right)
$$

Decreasing the time subscript by one unit in equation (20) implies that a consumer born at the beginning of period $t$ receives a bequest with present value (as of the beginning of period $t$ ) equal to

$$
\frac{1}{R_{t+1}} \frac{b_{t+1}}{\eta_{t}}=\frac{\gamma}{\beta+\gamma} \frac{1}{N_{t}}\left(\alpha Y_{t}+\frac{1-\phi}{\phi} I_{t}\right) .
$$

The present value of lifetime resources of a consumer born at the beginning of period $t$ can be calculated by substituting the wage from equation (11) and bequest received from equation (21) into equation (14) to obtain

$$
\theta_{t}=(1-\alpha) \frac{Y_{t}}{N_{t}}+\frac{\gamma}{\beta+\gamma} \frac{1}{N_{t}}\left(\alpha Y_{t}+\frac{1-\phi}{\phi} I_{t}\right)
$$

\subsection{Aggregate Behavior}

Let $\Theta_{t} \equiv N_{t} \theta_{t}$ denote the aggregate present value of lifetime resources of the cohort born at the beginning of period $t$. Equation (22) implies

$$
\Theta_{t} \equiv N_{t} \theta_{t}=\left(1-\frac{\beta}{\beta+\gamma} \alpha\right) Y_{t}+\frac{\gamma}{\beta+\gamma} \frac{1-\phi}{\phi} I_{t}
$$


Let $C_{t} \equiv N_{t} c_{t}$ be the aggregate consumption in period $t$ of the cohort of young consumers. Equations (17) and (23) imply

$$
C_{t}=\frac{1}{1+\beta+\gamma}\left[\left(1-\frac{\beta}{\beta+\gamma} \alpha\right) Y_{t}+\frac{\gamma}{\beta+\gamma} \frac{1-\phi}{\phi} I_{t}\right] .
$$

Let $X_{t} \equiv N_{t-1} x_{t}$ be the aggregate consumption in period $t$ of the cohort of $N_{t-1}$ old consumers (who were born at the beginning of period $t-1$ ). Equation (19) implies

$$
X_{t}=\frac{\beta}{\beta+\gamma}\left(\alpha Y_{t}+\frac{1-\phi}{\phi} I_{t}\right) .
$$

The aggregate consumption of all consumers in period $t$ is calculated by adding $C_{t}$ from equation (24) to $X_{t}$ from equation (25) to obtain

$$
C_{t}+X_{t}=\frac{1}{1+\beta+\gamma}\left[(1+\alpha \beta) Y_{t}+(1+\beta) \frac{1-\phi}{\phi} I_{t}\right] .
$$

Recall that $Y_{t}$ is the aggregate output of the consumption goods technology in period $t$, and $I_{t}$ is the amount of this output used as an input to the capital adjustment technology rather than consumed. Thus,

$$
I_{t}=Y_{t}-C_{t}-X_{t} .
$$

Now substitute aggregate consumption from equation (26) into equation (27) to obtain ${ }^{9}$

$$
I_{t}=\psi Y_{t}
$$

where

\footnotetext{
${ }^{9}$ Equations $(28,29)$ may be derived alternatively as follows. The cohort of consumers born at the beginning of period $t$ owns the entire capital stock, $K_{t+1}$, at the beginning of period $t+1$. It acquires capital by saving $(1-\alpha) Y_{t}-C_{t}$, and (see equation (21)) it inherits capital that has a present value at the end of period $t$ equal to $\frac{\gamma}{\beta+\gamma}\left(\alpha Y_{t}+\frac{1-\phi}{\phi} I_{t}\right)$. Therefore, the value, at the end of period $t$, of the capital stock carried into period $t+1$ is $q_{t} K_{t+1}=(1-\alpha) Y_{t}-C_{t}+\frac{\gamma}{\beta+\gamma}\left(\alpha Y_{t}+\frac{1-\phi}{\phi} I_{t}\right)$. Now use equation (10) to substitute $\frac{1}{\phi} I_{t}$ for $q_{t} K_{t+1}$, and use equation (24) for $C_{t}$ to obtain $\frac{1}{\phi} I_{t}=(1-\alpha) Y_{t}-\frac{1}{1+\beta+\gamma}\left[\left(1-\frac{\beta}{\beta+\gamma} \alpha\right) Y_{t}+\frac{\gamma}{\beta+\gamma} \frac{1-\phi}{\phi} I_{t}\right]+\frac{\gamma}{\beta+\gamma}\left(\alpha Y_{t}+\frac{1-\phi}{\phi} I_{t}\right)$. Simplifying this equation yields $I_{t}=\phi \frac{(1-\alpha) \beta+\gamma}{1+\beta+\gamma \phi} Y_{t}$.
} 


$$
0<\psi \equiv \phi \frac{(1-\alpha) \beta+\gamma}{1+\beta+\gamma \phi}<1
$$

The investment-output ratio $\psi$ depends on the strength of the bequest motive $\gamma$. In the special case in which $\gamma=0$, the investment-output ratio is $\psi=\phi \frac{\beta}{1+\beta}(1-\alpha)$ as in the laissez-faire special case in Abel (2000, Section $5)$. To determine the effect of $\gamma$ on $\psi$, differentiate the expression for $\psi$ in equation (29) with respect to $\gamma$ to obtain

$$
\frac{\partial \psi}{\partial \gamma}=(1-\psi) \frac{\phi}{1+\beta+\gamma \phi}>0
$$

Equation (30) implies that comparing two economies with identical technologies, and preferences that are identical except for the value of $\gamma$, the economy with a stronger bequest motive (higher $\gamma$ ) will have a higher investmentoutput ratio, $\psi$.

\subsection{The Dynamic Behavior of Aggregates}

The investment-capital ratio, $\frac{I_{t}}{K_{t}}$, is an important factor affecting the growth rate of the capital stock as well as the price of capital. Use equation (7) to substitute for $Y_{t}$ in equation (28) and divide both sides by $K_{t}$ to obtain

$$
\frac{I_{t}}{K_{t}}=\psi A k_{t}^{\alpha-1}
$$

where $k_{t} \equiv \frac{K_{t}}{N_{t}}$. Now divide both sides of the capital adjustment technology in equation (8) by $N_{t}$, and use the expression for the investment-capital ratio in equation (31) to obtain

$$
k_{t+1} \eta_{t+1}=a \psi^{\phi} A^{\phi} k_{t}^{1-(1-\alpha) \phi} .
$$

Take logarithms of both sides of equation (32) to obtain an AR(1) process for $\ln k_{t+1}$

$$
\ln k_{t+1}=[1-(1-\alpha) \phi] \ln k_{t}+\ln a+\phi \ln \psi+\phi \ln A-\ln \eta_{t+1} .
$$

Since $0<\alpha<1$ and $0<\phi<1, \ln k_{t+1}$ follows a stationary $\mathrm{AR}(1)$ process if the birth rate, $\ln \eta_{t+1}$, is serially uncorrelated. To analyze the impact of 
a bequest motive on the accumulation of capital, recall from equation (30) that the investment-output ratio, $\psi$, is an increasing function of the bequest motive parameter $\gamma$. Equation (33) implies that an increase in $\gamma$, which increases $\psi$, will increase the average value of the capital-labor ratio but will not affect the variance or serial correlation of $\ln k_{t+1}$. More precisely, an increase in $\gamma$ increases the mean of the stationary distribution of $\ln k_{t+1}$ but has no effect on any autocovariances of $\ln k_{t+1}$.

The equilibrium value of the (logarithm of the) price of capital is determined by substituting equation (31) into equation (9) and taking logarithms of both sides of the equation to obtain

$$
\ln q_{t}=-\ln \phi a+(1-\phi) \ln \psi+(1-\phi) \ln A-(1-\alpha)(1-\phi) \ln k_{t} .
$$

Use equation (34) lagged one period to obtain an expression for $\ln q_{t-1}$. Then subtract $[1-(1-\alpha) \phi] \ln q_{t-1}$ from $\ln q_{t}$, and use equation (33) to obtain

$\ln q_{t}=[1-(1-\alpha) \phi] \ln q_{t-1}-(1-\alpha)(\phi \ln \phi+\ln a)+(1-\alpha)(1-\phi) \ln \eta_{t}$.

If the birth rate, $\eta_{t}$, is serially uncorrelated, then the (logarithm of the) equilibrium price of capital, $\ln q_{t}$, follows a stationary $\mathrm{AR}(1)$ process, with the same serial correlation as $\ln k_{t+1}$, and this $\mathrm{AR}(1)$ process is independent of the strength of the bequest motive $\gamma$. Suppose that in period $t-1$ the price of capital equals its unconditional mean, and that the realization of the birth rate, $\eta_{t}$, is unusually large. According to equation (35), this baby boom in period $t$ causes the price of capital, $q_{t}$, to increase. If the birth rate is serially uncorrelated, the price of capital is rationally anticipated to fall back toward its unconditional mean in period $t+1$. The magnitude of the anticipated drop in the price of capital - or asset market meltdown - when the baby boomers retire in period $t+1$ is independent of the strength of the bequest motive. Therefore, the introduction of a bequest motive does not attenuate the asset market meltdown.

\section{Concluding Remarks}

Poterba's examination of age-specific asset holdings in the Survey of Consumer Finances leads him to conclude that consumers accumulate assets 
while they are of working age, but they hold on to these assets during retirement much more than would be predicted by a simple life-cycle model without lifetime uncertainty and without a bequest motive. He uses age-specific asset holdings, together with age-specific population data and projections, to calculate a time series of projected asset demand. He finds evidence that the price-dividend ratio of stocks in the United States has been positively related to his projected asset demand variable in various historical sample periods. Looking into the future, Poterba's projected asset demand variable increases over the next twenty years, and then remains fairly constant. Because the projected asset demand does not decline when the baby boomers retire, Poterba rejects the asset market meltdown hypothesis, which predicts a decline in stock prices when the baby boomers retire.

I have taken at face value Poterba's finding about age-specific asset holdings, and his finding of a positive effect of his projected asset demands on stock prices in historical data. I have also taken at face value his finding that projected asset demand will not fall when the baby boomers retire. However, I have shown that Poterba's conclusion that asset prices will not fall when the baby boomers are retired is not a necessary logical consequence of continued high levels of projected asset demand. The flaw in Poterba's conclusion is that he tries to forecast the price of capital by focusing only on the demand for capital, without taking account of the supply of capital. I have developed a rational expectations general equilibrium model with a bequest motive, and this model is consistent with Poterba's observations that retired consumers continue to hold a substantial amount of assets at the time of death and that a baby boom can drive up the price of capital. However, contrary to Poterba's conclusion, there is an anticipated decline in the price of capital when baby boomers retire, and this decline is not attenuated at all by the introduction of a bequest motive.

My finding that the equilibrium price of capital is invariant to the bequest motive is a consequence of the particular parametric specification of preferences and technology that I use. I regard this invariance result as a rhetorical device to make the point that one cannot predict the price of capital by focussing on the demand for capital while ignoring its supply. The effect of asset demands by retirees on asset prices in a more general context remains an open question worthy of further study. In considering the role of asset demands by retirees in a more general framework, different motives for these asset demands might be analyzed. Instead of using the bequest motive specified in this paper, positive asset demands by retirees can be gen- 
erated by a bequest motive based on altruism. Alternatively, precautionary saving to guard against longevity risk in the absence of perfect annuity markets would be a way to generate a demand for assets by retired consumers. Another direction for exploration is to examine alternative forms of the aggregate supply curve of capital, especially because this paper has illustrated the potentially important role of the supply of capital in determining the equilibrium price of capital.

\section{References}

[1] Abel, Andrew B., "The Effects of a Baby Boom on Stock Prices and Capital Accumulation in the Presence of Social Security," mimeo, The Wharton School of the University of Pennsylvania, December 2000.

[2] Brooks, Robin, "What Will Happen to Financial Markets When Baby Boomers Retire?" mimeo, International Monetary Fund, December 1999.

[3] Poterba, James M., "Demographic Structure and Asset Returns," mimeo, Massachusetts Institute of Technology, March 2000. 